\title{
Significados e sentidos do trabalho docente na educação infantil: reflexões a partir do materialismo histórico-dialético
}

\author{
Rosiris Pereira de Souza ${ }^{1}$ \\ Rodrigo Fideles Fernandes Mohn² \\ Kátia Augusta Curado Pinheiro Cordeiro da Silva ${ }^{3}$
}

\begin{abstract}
Resumo
Este artigo tem como objetivo apresentar uma reflexão sobre o conceito de trabalho para Marx e, a partir dessa reflexão, estabelecer relações e mediações que revelam significados e sentidos do trabalho docente na educação infantil. Nossa análise buscou, a partir de estudos sobre a categoria ontológica "trabalho", compreender as mediações e contradições postas ao trabalho docente na educação infantil no contexto da economia de mercado, refletindo assim sobre os processos de subsunção do trabalho docente ao capital. A análise teve como método o materialismo histórico-dialético, buscando revelar o fenômeno para além da imediaticidade, tendo como referencial Marx (1978, 1993, 2010, 2013); Marx e Engels (1984); Kosik (1976); Kopnin (1978); Duarte (1999, 2004); Frigotto (1989, 1998, 2009); Húngaro (2008). A aproximação com as categorias - significados e sentidos - foi pautada em Vigotski (2000); Leontiev (1978); Aguiar e Ozella (2006, 2013); Soares (2006); Aguiar e Soares (2008). A singularidade do trabalho docente na educação infantil é apresentada enquanto definibilidade específica deste fenômeno, em sua manifestação imediata e acessível, compreendendo que tal singularidade é produto histórico-social, apropriado por meio dos significados sociais sobre o trabalho educativo nessa etapa da formação humana e objetivado pelos professores ${ }^{4}$ da educação infantil (sentidos pessoais/subjetivos sobre o trabalho).
\end{abstract}

Palavras-chave: Trabalho, Trabalho docente, Educação Infantil Significados/Sentidos.

\section{Meanings and senses of the teaching work in early childhood education: reflections from dialectical historical materialism}

\begin{abstract}
This article aims to present a reflection on the concept of work for Marx and, based on this reflection, to establish relations and mediations that reveal meanings and senses of the teaching work in early childhood education. Our analysis sought, based on studies about the ontological category "work," to understand the mediations and contradictions posed to the teaching work in early childhood education in the context of the market economy, thus reflecting on the processes of subsumption of the teaching work to capital. The analysis was based on the historical-dialectical materialism method, seeking to reveal the phenomenon beyond its immediacy, having as references Marx (1978, 1993, 2010, 2013); Marx and Engels (1984); Kosik (1976); Kopnin (1978); Duarte (1999, 2004); Frigotto (1989, 1998, 2009); Húngaro (2008). The approach to the categories - meanings and senses - was based on Vygotsky (2000); Leontiev (1978); Aguiar and Ozella (2006, 2013); Soares (2006); Aguiar and Soares (2008). The uniqueness of the teaching work in early childhood education is presented as specific definability of this phenomenon, in its immediate and accessible manifestation, understanding that such uniqueness is a historical-social product, appropriated through social meanings about the educational work in this stage of human formation and objectified by teachers ${ }^{[1]}$ of early childhood education (personal/subjective meanings about the work).

Keywords: Work, Teaching work, Child education, Meanings/Senses.
\end{abstract}

\footnotetext{
${ }^{1}$ Doutora em Educação, UFG. E-mail: rosiris_periera_souza@ufg.br.

2 Doutor em Educação, PUC Goiás. E-mail: rodrigo.fideles@ hotmail.com.

3 Doutora em Educação; Professora associada da Universidade de Brasília - UnB no Departamento de Administração e Planejamento - PAD da Faculdade de Educação e no Programa de Pós-graduação em Educação. E-mail: katiacurado@unb.br.

${ }^{4}$ Neste artigo utilizamos termos no masculino genérico que é, resumidamente, o uso do gênero gramatical masculino para denotar o gênero humano como um todo (isto é, homens e/ou mulheres). No entanto, compreendemos ser muito importante destacar que o trabalho docente na Educação Infantil é exercido, majoritariamente, por mulheres.
} 


\section{Introdução}

Este texto apresenta parte dos resultados de uma pesquisa vinculada ao Grupo de Estudos e Pesquisas sobre Formação e Atuação de Professores/Pedagogos (GEPFAPe), cuja temática central abordou o trabalho docente na educação infantil. Neste artigo realizaremos uma reflexão conceitual sobre o trabalho docente na educação infantil a partir do materialismo histórico-dialético, buscando apreender o objeto em análise e suas múltiplas determinações. Assim, o trabalho docente na educação infantil foi apresentado como uma categoria singular na relação com a categoria trabalho, em sua dimensão ontológica e filosófica.

Considerando que o trabalho docente é uma categoria importante no campo da formação de professores, é apresentada, no presente texto, uma reflexão conceitual sobre a categoria "trabalho" fundamentada no materialismo histórico-dialético. Esse referencial se constituiu como fundamento teórico para uma compreensão ampliada sobre o trabalho docente, considerando suas atuais condições numa etapa específica da educação básica, ou seja, a educação infantil. Nessa perspectiva, a intenção inicial foi a compreensão da categoria "trabalho" e, a partir dessa compreensão, abordar a categoria "trabalho docente" para então apresentar as reflexões sobre as determinações que podem implicar em questões que emergem (dificuldades, desafios e descobertas) no campo de atuação docente na educação infantil.

Essa intenção parte do pressuposto defendido por Frigotto (2009, p. 169), cuja afirmação indica que "[...] os sentidos e significados do trabalho resultam e constituem-se como parte das relações sociais em diferentes épocas históricas [...]”. O autor pondera, coerentemente, que essa compreensão determina " [...] um ponto central da batalha das ideias na luta contra-hegemônica à ideologia e à cultura burguesas [...]”. Em sua lógica, esse pressuposto significa,

[...] compreender e tratar as relações de produção e de reprodução sociais, a linguagem, o pensamento e a cultura de forma histórico-dialética e, para não cairmos numa discussão abstrata, atemporal ou - nos termos de Marx - escolástica, que o sentido do trabalho, expresso pela linguagem e pelo pensamento, só pode ser efetivamente real no campo contraditório da práxis e num determinado tempo e contextos históricos (Frigotto, 2009, p. 169).

Na presente análise, o conceito de trabalho docente é entendido como prática social imersa em múltiplos contextos (ideológico, econômico, político e cultural). Sendo, portanto, 
um todo articulado e atravessado por diferentes aspectos e contradições que compõem a lógica da sociedade capitalista. Dizendo de outra forma, o trabalho docente é

[...] uma prática social contraditória, à medida que se efetiva no interior de uma sociedade de classes marcada por interesses antagônicos que se articula com os interesses burgueses e com os daqueles que constituem a classe dominada (Frigotto, 1989, p. 11).

Em acordo com Frigotto (2009, p.), captar os “[...] sentidos e significados do trabalho na experiência social e cultural das massas de trabalhadores é tarefa complexa e implica analisar como se produz a sociedade nos âmbitos da economia, da cultura, da política, da arte e da educação [...]", pois somente assim é possível apreender os significados em sua historicidade e compreender como são apreendidos na vida real pela classe trabalhadora.

\section{A categoria trabalho na sua dimensão ontocriativa}

Frigotto (2009) aponta que o surgimento de novos estudos e pesquisas buscou compreender e explicitar a origem e o desenvolvimento do sentido de trabalho que se tem hoje, qual seja: “[...] reduzido a emprego como quantidade de tempo pago por uma determinada atividade [...]” (p. 174), mostrando a importância de que a categoria trabalho seja compreendida na sua dimensão ontocriativa, em contraposição à forma histórica que assume no modo de produção capitalista.

Em Marx (2013, p. 255), o trabalho constitui-se, antes de tudo, de “[...] um processo entre homem e natureza, processo este em que o homem, por sua própria ação, medeia, regula e controla seu metabolismo com a natureza [...]", num confronto orgânico com a matéria natural. Nessa relação, o homem transforma a natureza e a si mesmo, ou seja, "[...] agindo sobre a natureza externa e modificando-a por meio desse movimento, ele modifica, ao mesmo tempo, sua própria natureza [...]”. De acordo com Marx e Engels (1984), o ato fundante que diferencia o homem de outros animais é justamente a produção material dos meios de vida.

Nesse movimento, o trabalho representa uma mediação eterna e necessária do homem com a natureza, sendo um ato criativo e teleológico pelo qual o homem se objetiva (Marx, 1993). Assim, nas relações dos homens com a natureza, o trabalho é a atividade pela qual o homem garante a produção da vida e a sobrevivência do gênero humano. 
Antunes (1995) afirma que a compreensão da categoria trabalho em Marx é fundamental para o entendimento da exploração posta na sociedade capitalista. Nesse contexto, o trabalho abstrato assume forma distinta do trabalho concreto, visto que, em tal condição, ao assumir a forma de trabalho alienado, o trabalho se constitui na própria negação da essência humana, ou seja, na própria impossibilidade da existência do desenvolvimento da omnilateralidade, aqui entendida enquanto possibilidade de realização do homem. Na relação com o trabalho abstrato, as objetivações assumem também um caráter estranhado, de maneira que nessas "[...] circunstâncias históricas o trabalho não se apresenta como uma objetivação criativa, mas como alienação [...]" (Húngaro, 2008, p. 52).

Para Marx (2010), a alienação pelo trabalho impede o desenvolvimento humano e, nesse ato, o desenvolvimento singular e genérico dos homens. Portanto, nessa ótica, apresenta-se como desrealização. Ou seja, um projeto de sociedade que se pretenda emancipador envolve necessariamente a luta pela superação do trabalho alienado, porém, é sempre importante frisar que o trabalho concreto como atividade humana consciente é ontologicamente insuprimível (Lukács, 1979).

A compreensão do trabalho em sua dimensão ontológico-filosófica é central para o desvelamento das relações sociais. De acordo com Húngaro (2008), na teoria marxiana, o trabalho - enquanto categoria - articula os complexos sociais na produção material da vida social. Nessa perspectiva, o trabalho passa a ser concebido como elemento fundante objetivação fundamental para o entendimento da sociedade e dos processos de exploração do homem pelo homem -, sendo, ao mesmo tempo, importante compreendê-lo dentro da lógica capitalista de produção, ou seja, na forma de trabalho alienado.

\section{O trabalho docente sob o contexto das relações sociais capitalistas}

A reflexão sobre o trabalho docente teve como referência as categorias: trabalho manual e intelectual, material e não material, produtivo e improdutivo no modo de produção capitalista, fundamentada em estudos que ampliam e diversificam as categorias marxianas sobre o trabalho na contemporaneidade, tais como Antunes (1995, 2001); Saviani (1994, 2003); Mascarenhas (2002); Frigotto (1998).

No século XIX, tinha-se clara a divisão entre o trabalho manual - responsável pela produção da riqueza social e da mais valia - e o trabalho intelectual, cuja ação controlava e 
explorava o trabalho operário. Nesse contexto, estava nítida a demarcação da relação entre o capital e o trabalho a partir de sua divisão social entre as classes (proprietários e não proprietários dos meios de produção).

Em relação à produção de valor, faz-se necessária a compreensão de que o trabalho produtivo, em Marx, indica o trabalho que amplia a acumulação e valorização do capital, ou seja, que produz valor de troca e mais-valia, enquanto o trabalho improdutivo é justamente o seu oposto.

Segundo Kuenzer e Caldas (2009), o trabalho docente não escapa à essa dupla face do trabalho (concreto e abstrato), cuja função é produzir valores de uso e valores de troca. Para as autoras, a produção de valores de uso no processo de trabalho se desenvolve na atividade do homem que realiza uma transformação sobre o objeto de sua ação, subordinada a um determinado fim, ou seja, à realização de um produto ou serviço para atender às necessidades humanas. Portanto, uma parte da natureza será adaptada às necessidades do homem por meio da mudança de sua forma sem que esse processo tenha como finalidade a produção de excedentes para acumular riqueza (Kuenzer e Caldas, 2009).

Quanto à produção de valor de troca, Kuenzer e Caldas (2009) pontuam a necessidade de se considerar a mudança de circunstâncias, pois é com o advento do capitalismo que o "[...] processo de trabalho passa ser a produção de valor de troca, valor que se auto expande, com a finalidade de acumular riqueza por meio da produção do trabalho excedente, que será apropriado pelo capitalista [...]”. Nessa lógica, é sob o marco do capital que o capitalista “[...] detém a propriedade dos meios de produção e da força de trabalho [...]", aspecto que determina "[...] o processo de alienação do trabalhador, que perde controle de seu trabalho, das decisões sobre ele e, em decorrência, a posse do produto de seu esforço [...]" (Kuenzer e Caldas, 2009, p. 22).

Nesse processo, ao produzir relações sociais alienantes, o trabalho passa a ser a negação do humano, ao mesmo tempo em que continua a produzir o próprio homem, afirmando-o como indivíduo e como categoria (Marx e Engels, 1984).

Sobre o trabalho material e não material, pode-se dizer, de forma bem ampla, que o trabalho material - como o próprio termo diz - tem a ver com sua materialidade, concretude e com a circulação das mercadorias entre a produção e o consumo, dizendo de outro modo, é o que produz mercadorias tangíveis. No caso do trabalho não material, o produto não se separa 
do produtor. Para que se compreenda a presença do capitalismo no domínio da produção não material é importante destacar que esta pode ser de dois tipos:

1. Resulta em mercadorias, valores de uso que tem uma forma distinta dos produtores e consumidores e independente destes; essas mercadorias podem existir, pois, durante um intervalo entre a produção e o consumo e nesse intervalo circular como mercadorias vendáveis, tais como os livros, quadros, em uma palavra, todos os produtos artísticos distintos da execução artística ou do artista que os executa. [...] 2. A produção não pode separar-se do ato de produzir, como ocorre com todos os artistas, oradores, atores, professores, médicos, sacerdotes etc. (Duarte et al., 2011, p. 43).

Ao considerar as categorias marxianas em sentido estrito no trabalho docente, pode-se afirmar a existência de uma natureza e especificidade distinta do trabalho material e produtivo. Assim, é compreendido como parte de uma totalidade constituída pelo trabalho sob o capitalismo, submetido à sua lógica e contradições. O trabalho docente não escapa da dupla face do trabalho na produção de valores de uso e valores de troca (Kuenzer e Caldas, 2009).

O trabalho do professor possui especificidades, as quais dizem respeito ao ser do professor, uma vez que este não atua sobre a natureza (matéria-prima), mas sim com pessoas (natureza humana), pois seu trabalho envolve sujeitos em processo de humanização. Ainda, pode-se dizer que ao final do trabalho do professor não resta um produto que se separa do trabalhador, ou seja, o produto do trabalho do professor está encalacrado nele mesmo, portanto, é um trabalho não material. Dessa forma, a depender da natureza administrativa das instituições - se são públicas ou privadas ou ainda da natureza das mediações - que pode ser imediatamente/diretamente improdutivo e mediatamente/indiretamente produtivo (Frigotto, 2009).

Nas instituições públicas, uma especificidade importante do trabalho do professor em relação ao trabalho produtivo e material indica que - apesar de todo o processo de fragmentação, precarização, intensificação e regulação, por ser (imediatamente) improdutivo e não material - o trabalho docente ainda conserva relativa autonomia em relação ao controle externo. A perda do controle e da autonomia sobre o trabalho são características marcantes do processo de flexibilização e precarização na sociedade capitalista contemporânea.

Partindo do suposto de que no modo de produção capitalista o trabalho docente (Kuenzer e Caldas, 2009) está presente na totalidade da categoria trabalho, se constituindo 
como expressão da divisão técnica e social do trabalho - tal como está constituída na sociedade capitalista, mesmo não produzindo mercadorias (ou seja, mesmo possuindo natureza distinta da produção material) -, é possível inferir que esse trabalho docente está atravessado por contradições. E, que tais contradições, ao mesmo tempo, marcam a dupla face ou movimento pendular dessa atividade (Antunes, 1995), quais sejam: realização e desrealização, humanização e desumanização.

Assim, com base nas análises de Oliveira (2003; 2004), pode-se afirmar que no modo de organização capitalista o trabalho docente está submetido a processos de maior intensificação, precarização, flexibilização e fragmentação, podendo resultar em processos de alienação e sofrimento.

No entanto, é extremamente importante ponderar que tais processos não se dão totalmente sem movimentos de resistência dos professores. De acordo com Caldas (2007), nas relações de dominação presentes na sociedade capitalista, o trabalho docente pode conter, simultaneamente, dois movimentos contraditórios: reações de desistência e comportamentos de resistência. Deste modo, entendemos que o trabalho docente não serve exclusivamente aos interesses das relações de dominação do capital, pois, exatamente na contramão disso, também possui e expressa interesses e significados que buscam possibilidades emancipatórias. Assim, “[...] a escola passa a ser interpretada não como um espaço totalmente controlado pelo capital, nem tampouco como o terreno da plena realização, mas como lugar contraditório da reprodução e contestação [...]" (Caldas, 2007, p. 3-4).

Essa análise impõe a necessidade de compreensão da natureza própria do trabalho educativo, produzido e reproduzido por meio da tensão dialética entre as determinações estruturais da realidade social e de suas próprias determinações específicas, por meio das quais se produz a alienação e, ao mesmo tempo, são engendrados espaços de autonomia relativa (Caldas, 2007).

Não há como negar que o trabalho docente está submetido ao forte impacto das transformações e avanços materiais e imateriais alcançados na sociedade capitalista contemporânea e, portanto, às alterações em sua natureza, formas de organização e consequentes relações e condições de trabalho (Oliveira, 2004) que objetivam, sobretudo, mas não somente, responder às demandas mercadológicas da sociedade capitalista contemporânea.

A partir das contribuições teóricas de Marx - no âmbito do modo de produção 
capitalista -, pode-se compreender que elementos complexos e multifacetados são inscritos na categoria trabalho. Trazendo esse debate para o campo do trabalho docente, pode-se reafirmar que o entendimento da categoria trabalho e seu movimento pendular (trabalho concreto/trabalho abstrato) é basilar para uma compreensão ampliada do trabalho docente e sua manifestação no campo da educação infantil.

\section{O trabalho docente na educação infantil}

Para as reflexões sobre o trabalho docente na educação infantil, antes é importante destacar ter sido somente a partir da Constituição Federal de 1988 e da Lei de Diretrizes e Bases da Educação Nacional no 9.394 de 1996 que a Educação infantil foi integrada efetivamente à educação básica. Assim, instituiu-se uma nova compreensão relativa à formação e atuação de professores para essa demanda. As mudanças no campo da legislação se constituíram em aspectos importantes e determinantes para as transformações das concepções sobre o trabalho docente nessa etapa, revelando novos significados e sentidos.

No atual contexto, cada vez mais, são apresentadas situações instáveis e precárias para os trabalhadores em geral e da educação - em especial, com perdas de direitos e conquistas, ampliação do desemprego estrutural e desvalorização social -, tudo isso orquestrado pela lógica destrutiva do capital (Antunes, 2001).

A partir dessa compreensão ampla sobre as condições de trabalho, é importante destacar as condições de trabalho dos professores que atuam na educação infantil. De acordo com indicadores educacionais e pesquisas recentes, a educação infantil é a etapa educativa que agrega o maior número de professores sem a formação mínima estabelecida pela legislação nacional. Em algumas pesquisas, é marcante a questão da desvalorização dos professores dessa etapa, visto que acumulam as piores condições de trabalho, a maior jornada laboral e os menores salários em relação aos demais professores de outros níveis, etapas e modalidades da educação (Gatti e Barreto, 2009; Oliveira e Vieira, 2012; Vieira, 2013; Oliveira, 2013).

É no contexto do modo capitalista de produção que o trabalho docente na educação infantil deve ser analisado, reafirmando a ideia de que a escola e as instituições de atendimento da educação infantil são locais de trabalho e que os professores, inseridos em relações de trabalho, são trabalhadores e compõem a classe-que-vive-do-trabalho (Antunes, 
1995, 2001) e, portanto, são afetados diretamente ou indiretamente pelas grandes transformações vividas pela sociedade e pela nova forma de ser da classe trabalhadora nos dias de hoje. Esse cenário reafirma a importância e a atualidade das postulações de Marx $(1978,1984)$ sobre o trabalho na sociedade capitalista e sobre as formas de subsunção formal e real do trabalho ao capital. Sem desconsiderar, é claro, a natureza e especificidade do trabalho docente que não se concretiza na transformação direta da matéria natural (Saviani, 2003). No seu trabalho, o professor de educação infantil atua com outros sujeitos em processos de aprendizagem e desenvolvimento, em geral menos experientes em relação aos conhecimentos científicos e à cultura.

Mesmo que o trabalho do professor possua uma especificidade que o diferencia do sentido estrito de trabalho material, proposto por Marx no século XIX, isso não o isenta de ser um trabalho que passou pelo processo de assalariamento (seja na instituição pública ou privada), sendo submetido a processos de alienação, aproximando-o da condição de proletariado, termo entendido como expressão concentrada dos sofrimentos que infligem os trabalhadores (trabalho produtivo), no modo de produção capitalista (Vásquez, 1977). Nessa perspectiva, as observações de Marx sobre o trabalho do professor são lapidares, pois:

[...] um mestre escola é um trabalhador produtivo quando trabalha não só para desenvolver a mente das crianças, mas também para enriquecer o dono da escola. Que este inverta seu capital numa fábrica de ensinar, em vez de numa de fazer salsicha, em nada modifica a situação. $O$ conceito de trabalho produtivo não compreende apenas uma relação entre atividade e efeito útil, entre trabalhador e produto do trabalho, mas também uma relação de produção especificamente social, de origem histórica, que faz do trabalhador o instrumento direto de criar mais-valia. Ser trabalhador produtivo não é nenhuma felicidade, mas azar [...] (Marx, 1984, p. 584).

De acordo com os estudos de Lombardi (2010), em Marx, a educação é:

[...] um campo da atividade humana e os profissionais da educação não construíram esse campo segundo ideias próprias, mas em conformidade com condições materiais e objetivas, correspondendo às forças produtivas e relações de produção adequadas aos diferentes modos e organizações da produção, historicamente construídas pelos homens e particularmente consolidadas nas mais diferentes formações sociais (Lombardi, 2010, p. 231).

Conforme a presente análise, é possível afirmar - a partir da compreensão dos excertos anteriores - que o trabalho dos professores, sob o capitalismo atual, se depara com os 
impactos e transformações do mundo do trabalho. Tal situação compromete e altera sua forma de ser, sua natureza e formas de organização, modificando também as relações e condições de trabalho (Lancillotti, 2008; Oliveira, 2004).

Segundo Antunes e Alves (2004, p. 342), mesmo “[...] os trabalhadores improdutivos, criadores de antivalor no processo de trabalho, vivenciam situações muito aproximadas com aquelas experimentadas pelo conjunto dos trabalhadores produtivos $[\ldots .$. ". Ou seja, de acordo com esse autor, assistimos a uma "[...] crescente imbricação entre trabalho produtivo e improdutivo no capitalismo contemporâneo [...]" (Antunes, 2001, p. 102-103), havendo diminuição da distinção entre proletários e assalariados, além de uma noção ampliada da classe trabalhadora.

Nessa perspectiva, é desenvolvido o entendimento de que o trabalho docente na educação infantil - assim como nas demais etapas, modalidades e níveis da educação na instituição pública - é trabalho não material (porque o produto não se separa do produtor); é trabalho improdutivo (nas instituições públicas e na relação direta e imediata), porque não produz mais valia na relação capital/trabalho e; é produtivo quando se considerar as relações indiretas e mediatizadas (Frigotto, 1989).

Assim, é afirmada a perspectiva de que o trabalho do professor da educação infantil não escapa à lógica da acumulação para o capital, porque ao se realizar produz conhecimentos e/ou trabalhadores para o capitalismo desde a mais tenra idade (natureza mediata e indireta). Segundo Kuenzer e Caldas (2009) essa vinculação é ainda mais ampla, pois decorre da afirmação de que o trabalho docente (sob a égide do capitalismo) se realiza pela venda da força de trabalho do professor para instituições privadas; pela qualificação científicotecnológica de trabalhadores para atender às demandas do trabalho capitalista; pelo disciplinamento com vista à subordinação; pela produção de ciência e tecnologia vinculada aos interesses da burguesia.

É importante considerar também o movimento contraditório do trabalho docente na sua dupla face, pois este também se organiza no sentido de formar indivíduos críticos dentro de uma perspectiva de superação da sociedade capitalista - justamente em contraposição à premissa anterior de atendimento único à lógica mercadológica -, porque, ao reproduzir a sociedade capitalista, a educação reproduz também suas contradições internas. Nessa perspectiva, a presente reflexão se orienta em acordo com Duarte $(2007$, p. 8), quando ele 
afirma que,

[...] a reprodução da sociedade é também a reprodução das contradições que permeiam a sociedade. Uma dessas contradições é a existente entre o fato de que, por um lado, a sociedade capitalista forma o indivíduo reduzindo-o a alguém que ocupa um lugar na divisão social do trabalho e, por outro lado, essa mesma sociedade produz, contraditoriamente, no indivíduo, necessidades de ordem superior, que apontam para a formação da individualidade para-si, isto é, para a formação de um indivíduo [...] que mantém uma relação consciente com sua vida cotidiana, mediatizada pela relação também consciente com as objetivações genéricas para-si (ciência, arte, filosofia, moral e política) (Duarte, 2007, p. 8).

No trabalho realizado nas instituições de educação infantil, a busca se expressa nas contradições e nas possibilidades que incidem sobre esse trabalho em suas múltiplas formas sociais dentro do modo de produção capitalista.

Os professores da educação infantil - e os trabalhadores em geral, em determinadas situações históricas - não compreendem totalmente as determinações sociais que incidem sobre seu campo de atuação profissional, pois, geralmente, as respostas dadas às dificuldades e aos desafios que emergem no exercício da carreira voltam-se para questões presentes na cotidianidade e imediaticidade (Heller, 2004). Tais questões levam a processos de alienação e crise mediante as demandas que se manifestam no trabalho docente, em alguns casos, por meio de movimentos de acomodação, abandono da profissão e/ou desmotivação. Em muitos casos, os professores não compreendem plenamente as várias questões que estão envolvidas em suas condições de trabalho, revelando haver uma tendência em considerar as dificuldades e os desafios do trabalho descolados de relações sociais mais amplas; desconectados de outros aspectos importantes da totalidade social.

$\mathrm{Na}$ educação infantil, os significados e sentidos do trabalho docente podem ser apropriados, elaborados e atribuídos pelos professores numa relação imediata com os fatores citados anteriormente. Esses fatores são constituintes de sentidos alienados e alienantes que inibem ou dificultam a apropriação do significado social concreto do trabalho docente realizado com crianças de zero até seis anos de idade.

\section{Considerações finais}

A atividade docente na educação infantil se constitui em trabalho quando passa a ser compreendida: a) “[...] como uma práxis humana, material e não material que objetiva a 
criação das condições de existência, e que portanto não se encerra na produção de mercadorias [...]" (Kuenzer, 1998, p. 55); b) como ofício de "[...] produzir, direta e intencionalmente, em cada indivíduo singular, a humanidade que é produzida histórica e coletivamente pelo conjunto dos homens [...]" (Saviani, 2003, p. 11) e; c) como "[...] prática social específica, no terreno da reprodução social, que carrega consigo a contradição estruturante da sociedade capitalista [...]" (Caldas, 2007, p. 2).

Nessa perspectiva, é muito importante a compreensão dos professores sobre a subordinação do seu trabalho à ordem capitalista e às suas contradições internas, pois, isso pode ajudar a desvelar os fatores reais que condicionam seu trabalho. Os determinantes que estão relacionados com as principais dificuldades e desafios no exercício da carreira e no processo de desenvolvimento profissional dos professores da educação infantil indicam os significados histórico-sociais atribuídos a este trabalho, marcados por circunstâncias alienantes e alienadas. Para o professor, a alienação está na dissociação entre significado e sentido do trabalho (Basso, 1994), pois depende de determinações que envolvem o grau de desenvolvimento das forças produtivas na sociedade.

A ideia defendida no presente artigo é a de que sob relações sociais de dominação, o significado e o sentido das ações dos professores podem separar-se, tornando-se alienados. Estudos de Leontiev (1978) mostram que, nessas condições, o sentido pessoal da ação não corresponde mais ao seu significado, pois o trabalho, em tais circunstâncias, passa a ser entendido pelo trabalhador apenas como meio de existência e, assim sendo, deixa de desenvolver novas capacidades e necessidades humanas (no sentido das potencialidades do gênero humano).

As contradições observadas em relação aos significados e sentidos do trabalho docente na educação infantil indicam duas categorias fundamentais para sua compreensão: a alienação e a emancipação. Tais categorias possibilitam a inferência de que os significados e sentidos são mediados, simultaneamente, por processos de alienação (pelo fato do trabalho docente estar formalmente subsumido à lógica capitalista na relação entre capital e trabalho) e, ao mesmo tempo, por processos de emancipação (pelo fato do trabalho docente não se concretizar como trabalho material e não ser diretamente produtivo na esfera do valor de troca nas instituições públicas de ensino).

Essa contradição nos permite afirmar que os significados sobre o trabalho docente na 
educação infantil fixados na sociedade capitalista podem ser ressignificados. Indica ainda que os significados constituídos sob o capitalismo - para o trabalho docente na educação infantil não são imparciais ou neutros em relação aos interesses de classe e gênero, apesar dessa compreensão nem sempre estar completamente presente nas elaborações e atribuições de sentidos pelos professores dessa etapa educativa, visto que, as contradições se constituem em linhas de forças presentes no cotidiano do trabalho docente na educação infantil, cuja fragmentação, intensificação, desvalorização e precarização da atividade docente distanciam os sentidos pessoais dos significados socialmente referenciados para esse trabalho. Assim, podemos inferir que os sentidos, ora são configurados/conformados em consonância com os significados naturalizados ideologicamente e determinados por aspectos objetivos e subjetivos, ora são resistentes aos mesmos - em movimento emancipador -, por meio da contradição que recapitula o movimento pendular (dupla face) do trabalho na sociedade capitalista, que possui uma dimensão ontológica de criação da vida humana, mas, quando submetido a determinadas circunstâncias, carrega elementos alienados e alienantes.

Nessa direção, em acordo com Basso (1994), se o sentido do trabalho docente atribuído pelo professor for apenas o de garantir sua sobrevivência e, se esse trabalhador não tiver consciência de sua participação na produção das objetivações genéricas, o sentido do seu trabalho será alienado e distante, visto que não estabelece relações com seu significado social e, por consequência, não estabelece relações conscientes do indivíduo com a genericidade. É justamente nessa busca da relação consciente com as objetivações produzidas socialmente e mediadas pelas circunstâncias e condições efetivas que as práticas sociais (incluindo o trabalho docente na educação infantil) podem superar os mecanismos de alienação.

\section{Referências}

AGUIAR, W. M. J.; OZELLA, S. Núcleos de significação como instrumento para a apreensão da constituição dos sentidos. Psicol. cienc. prof., Brasília, v. 26, n. 2, p. 222-245, jun. 2006. Disponível em: http://pepsic.bvsalud.org/scielo.php?script=sci_arttext\&pid= S1414-98932006000200006\&lng=pt\&nrm=iso. Acesso em: 08 mar. 2018.

AGUIAR, W. M. J. de; OZELLA, S. Apreensão dos sentidos: aprimorando a proposta dos núcleos de significação. Revista brasileira de Estudos Pedagógicos. v. 94, n. 236, p. 299-322, jan./abr. Brasília, 2013.

ANTUNES, R. Adeus ao trabalho? Ensaio sobre as metamorfoses e a centralidade do mundo 
do trabalho. São Paulo: Cortez, 1995.

ANTUNES, R. Os sentidos do trabalho: ensaio sobre a afirmação e a negação do trabalho. 5. ed. São Paulo, Boitempo, 2001.

ANTUNES, R.; ALVES, G. As mutações no mundo do trabalho na era da mundialização do capital. Educação \& Sociedade, Campinas, v. 25, n. 87, p. 335-351, maio/ago. 2004.

BASSO, I. S. As condições subjetivas e objetivas do trabalho docente: Um estudo a partir do ensino de história. 1994. 141 f. Tese (Doutorado em Educação) - Universidade Estadual de Campinas, Campinas, 1994.

CALDAS, A. do R. Desistência e resistência no trabalho docente: um estudo das professoras e professores do ensino fundamental da rede municipal de educação de Curitiba. 2007. $173 \mathrm{f}$. Tese (Doutorado em Educação) - Universidade Federal do Paraná, Curitiba, 2007.

DUARTE, N. Educação escolar, teoria do cotidiano e a escola de Vigotski. Campinas: Autores Associados, 2007.

DUARTE, N. et al A Pedagogia Histórico-Crítica e o Marxismo: equívocos de mais uma crítica à obra de Demerval. Revista HISTEDBR On-line, Campinas, 2011.

FRIGOTTO, G. A polissemia da categoria trabalho e a batalha das ideias na sociedade de classes. Revista Brasileira de Educação. São Paulo, v.14, n. 40, p. 168-194, jan./abr. 2009.

FRIGOTTO, G. A produtividade da escola improdutiva: um (re)exame das relações entre educação e estrutura econômico-social e capitalista. 3 ed. São Paulo: Cortez: Autores Associados, 1989.

FRIGOTTO, G. Educação e crise do trabalho: Perspectivas de final de século. Petrópolis: Vozes, 1998.

GATTI, B. A.; BARRETO, E. S. de S. Professores do Brasil: impasses e desafios. Brasília: UNESCO, 2009.

HELLER, A. Estrutura da vida cotidiana. Rio de Janeiro: Paz e Terra, 2004.

HÚNGARO, E. M. Trabalho, tempo livre e emancipação humana: os determinantes ontológicos das políticas sociais de lazer. 2008. 243 f. Tese (Doutorado) - Universidade de Campinas, Campinas, 2008.

KOPNIN, P. V. A dialética como lógica e teoria do conhecimento. Rio de Janeiro: Civilização Brasileira, 1978.

KOSIK, K. Dialética do concreto. Rio de Janeiro: Paz e Terra, 1976. 
KUENZER, A. Z. Desafios teórico-metodológicos da relação trabalho-educação e o papel social da escola. In: FRIGOTTO, G. Educação e crise do trabalho. Rio de Janeiro: Vozes, 1998.

KUENZER, A. Z.; CALDAS, A. Trabalho docente: comprometimento e desistência. In: OLIVEIRA, M. A.; FIDALGO, N. L. R. (Orgs.). A intensificação do trabalho docente: tecnologia e produtividade. Campinas: Papirus, 2009.

LANCILLOTTI, S. S. P. Trabalho docente: forma transitória de trabalho. Revista HISTEDBR on-line, Campinas, n. 30, p. 334-334, jun. 2008. Disponível em: http://www.histedbr.fe. unicamp.br/revista/edicoes/30/rdt04_30.pdf. Acesso em: 11 out. 2016.

LEONTIEV, A. O desenvolvimento do psiquismo. Lisboa: Horizonte Universitário, 1978.

LOMBARDI, J. C. Reflexões sobre educação e ensino na obra de Marx e Engels. 2010. Tese (Livre Docência em Educação) - Universidade de Campinas, Campinas, 2010.

LUKÁCS, G. Ontologia do Ser Social - os princípios ontológicos fundamentais de Marx. São Paulo: Ciências Humanas, 1979.

MARX, K.; ENGELS, F. A ideologia alemã. Teses sobre Feuerbach. São Paulo: Moraes, 1984.

MARX. K. O Capital I, Capítulo VI (Inédito): Resultados do processo imediato de produção. São Paulo: Ciências Humanas, 1978.

MARX. K. Manuscritos econômico-filosóficos. Tradução de Jesus Ranieri. São Paulo: Boitempo, 2010.

MARX. K. Manuscritos económicos-filosóficos. Lisboa: Edições 70, 1993.

MARX. K. O capital: crítica da economia política: Livro I: O processo de produção de capital. Tradução de Roberto Enderle. São Paulo: Boitempo, 2013.

MASCARENHAS, Â. C. B. O trabalho e a identidade politica da classe trabalhadora. Goiânia: Alternativa, 2002.

OLIVEIRA, D. A.; VIEIRA, L. M. F. Trabalho na Educação Básica: a condição docente em sete estados brasileiros. Belo Horizonte: Fino Traço, 2012.

OLIVEIRA. D. A. A profissão docente na Educação Infantil. Revista salto para o futuro Docência na educação infantil. Ano XXIII - boletim 10 - junho, 2013.

OLIVEIRA. D. A. A reestruturação do trabalho docente: precarização e flexibilização. Educ. Soc., Campinas, v. 25, n. 89, p. 1127-1144, set./dez. 2004. Disponível em: http://www.cedes. unicamp.br. Acesso em: 15 jul. 2016.

SAVIANI, D. O Trabalho como princípio educativo frente as novas tecnologias. In: 
Polyphonía, v. 32/2, jul./dez. 2021270

FERRETI, C. J. (Org.). Tecnologias, trabalho e educação. Rio de Janeiro: Vozes, 1994.

SAVIANI, D. Pedagogia histórico-crítica: primeiras aproximações. 8 ed. Campinas: Autores Associados, 2003.

VÁSQUEZ, A. S. Filosofia da Práxis. Rio de Janeiro: Paz e Terra, 1977.

VIEIRA, L. M. F. O perfil das professoras e educadoras da Educação Infantil no Brasil. Revista salto para o futuro - Docência na educação infantil. Ano XXIII - boletim 10 - jun., 2013.

VIGOTSKI, L. S. A construção do pensamento e da linguagem. São Paulo: Martins Fontes, 2000.

Recebido em: 22 set. 2020.

Aceito em: 03 mar. 2021. 